\title{
Sidi en su marginalidad: notas sobre la novela de Arturo Pérez-Reverte
}

\author{
Sidi between its Margins: \\ Notes about Arturo Pérez-Reverte's novel \\ Francisco Javier Hernández Ruiz \\ (Investigador independiente ${ }^{1}$ )
}

\begin{abstract}
RESUMEN
Aproximación a la especificidad del ingreso de Arturo Pérez-Reverte en la materia cidiana, a través de su novela Sidi. Un relato de frontera (2019). El artículo revisa algunas de las operaciones discursivas llevadas a cabo en la obra. La voz narrativa busca efectos de honestidad mediante la oscilación entre la descripción neutra y el uso del estilo indirecto libre. Así, presenta la interioridad del personaje, a la vez que marca en la descripción los límites de la representación del horror bélico. La identidad del protagonista, imbuido de esos efectos de honestidad, es presentada como una incógnita inicial y se dibuja, así, como la de un héroe moral antes que militar, que se aproxima a la figura literaria del samurái.
\end{abstract}

\section{Palabras Clave}

Arturo Pérez-Reverte, Sidi, representación de la guerra, samurái, transculturalidad.

\begin{abstract}
Approach to Arturo Pérez-Reverte's ingress in the Cidian matter by means of his novel Sidi: A story of border towns (2019). The article revises the discursive operations conducted in the work with the central figure of Rodrigo Díaz de Vivar. The narrative voice seeks an honesty effect through the fluctuation between the neutral description and the use of the free indirect speech. Thus, the novel offers the interiority of the character, while marking the boundaries of the representation about the war horror. The protagonist's identity, filled with these effects of honesty, is presented as an original mystery, which places us on the path of an inquiry about how Reverte's Cid should have been or how he is. Some of his ethic boundaries opens him to us as a moral hero rather than a soldier, bringing him closer to the literary figure that could unify both aspects: the samurai.
\end{abstract}

\section{KeYWORDS}

Arturo Pérez-Reverte, Sidi, representation of war, samurai, transcultural studies.

Recibido: 05/05/2021

Aceptado: 20/07/2021

1. Doctor en Comunicación e Interculturalidad por la Universitat de València. 
A lo largo del paso de los años se han sucedido las obras y estudios referidos a la figura central de uno de nuestros principales hitos literarios: el cantar de gesta bautizado como Cantar del Mio Cid. ${ }^{2}$ Desde los primeros testimonios escritos sobre sus hazañas, en los siglos XII y XIII, antes incluso de la composición y plasmación del Cantar en el manuscrito firmado por Per Abbat (1207), la historia de su protagonista, Rodrigo Díaz de Vivar se había prestado a diversos acercamientos y reformulaciones, y pronto iba a servir de inspiración para la creación de otras obras constituyentes del llamado ciclo cidiano ${ }^{3}$. Las líneas generales del argumento del Cantar son de sobra conocidas. Rodrigo Díaz de Vivar, el Cid Campeador, es desterrado por el rey Alfonso vi. El Cantar sólo se detiene en el recuento de algunos de sus logros militares principales, a raíz de su exilio, entre los que será culminante la conquista de la lejana e inexpugnable Valencia. El Cid, pese a su injusto destierro, se mantiene fiel al rey hasta el punto de alcanzar su perdón y quedar restituido en su honor públicamente. Casará a sus hijas con los infantes de Carrión, quienes, por envidia y despecho, maltratan a sus esposas, las mancillan y las abandonan medio muertas en medio de un bosque. El Cid ve perdida su honra privada y, a partir de ese momente, la recuperación pasará por recurrir al proceso legal pertinente para declarar nulos los matrimonios y que asíle sea reintegrada con creces ${ }^{4}$.

Con la publicación de su novela Sidi (2019), Arturo Pérez-Reverte entra de alguna manera a formar parte también del ciclo o materia cidiana. Boix Jovaní (2021) ha estudiado magistralmente, en su reciente artículo, «De Per Abbat a Pérez-Reverte: el Cid, entre la tradición y el superventas en Sidi $\gg$, la manera en la que las diferentes fuentes y conocimientos especializados sobre el Cid emergen en la escritura revertiana, como si se tratase de un palimpsesto en el que se revelan las anteriores escrituras fundiéndose con la nueva ${ }^{5}$. El propio autor cartagenero, en su obra anterior a Sidi — aunque publicada el mismo año-, Una historia de España (2019), hace mención del Campeador, denunciando la manipulación que habría padecido su figura durante el franquismo, a causa de la apropiación de la misma que hicieron falangista y sectores afines, e intenta presentárnoslo de manera más próxima a como tuvieron que ser realmente los hechos históricos: cómo se mantuvo fiel al rey, pese al destierro; cómo se dedicó a sobrevivir, batallando unas veces del lado de reyes cristianos y otras de reyes moros, hasta que Alfonso VI necesitó de su servicio; o cómo respondió cumplidamente a ese servicio, conquistando Valencia, donde, en torno a los cincuenta años, moriría de muerte natural. Desde esa perspectiva, más ajustada a lo que fue o pudo ser la historia de Rodrigo Díaz, es desde donde nuestro autor se adentra en

\footnotetext{
2. Véase la completísima edición de Montaner (2011).

3. Véase Alvar (1997). Los ciclos de los que guardan testimonio los antiguos romances pasaran a ser, siglos más tarde, videojuegos, series o películas de dibujos animados, habiendo franqueado antes otras etapas artísticas, como por ejemplo la operística, con Jules Massaenet, Le Cid (1885), y su magnífica aria, «Ô souverain, ô juge, ô père», que tan magistralmente interpretase el tenor José Carreras en 1994 durante uno de los famosos conciertos de Los tres tenores.

4. Véase solamente Fletcher (2001), entre una inmensa bibliografía sobre su figura histórica y el personaje o personajes literarios que ésta desencadena.

5. Habíamos redactado y presentado estas notas sobre la novela de Pérez-Reverte antes de que fuera publicado y pudiéramos leer el completísimo trabajo de Boix (2021). La profundidad, exhaustividad y originalidad del mismo nos exime, de algún modo, de intentar abarcar tantos aspectos como en él se desbrozan y analizan. Nuestro trabajo aquí parte, en cambio, del conocimiento de algunos aspectos de la obra novelística anterior de Pérez-Reverte, que fueron examinados en nuestra tesis doctoral (Hernández, 2020). Y del intento de imbricar esta nueva novela, Sidi, dentro de la trayectoria creativa del escritor y académico.
} 
las peripecias de un Cid que, a los pocos días de ser desterrado, se mueve por tierras fronterizas vendiendo sus servicios para sobrevivir'6.

Como apunta buena parte de la crítica, se puede señalar la ligazón del Cid de Pérez-Reverte con otros protagonistas de sus obras, y adscribirlo a esa estirpe de héroes cansados que habitan las novelas revertianas, como alguien que ha conseguido una visión más o menos ajustada y desengañada de la realidad, y que se ha creado una imagen de sí mismo a la que se aferra con amarga lucidez para no caer en el vacío existencial y en el sinsentido del mundo que le rodea ${ }^{7}$. Otro eslabón reconocible sería, como indica Muñoz Ogayar (2009), la presencia de una sub-trama técnica, fruto de la nutrida documentación del autor, y que en este caso consistiría en el acopio y empleo de una serie de términos especializados sobre combate, medida del tiempo y del espacio propios de la época, así como de léxico, expresiones y giros lingüísticos del castellano medieval. Sin embargo, los eslabones que conectan la escritura de Sidi con otros escritos del novelista van más allá, y merece la pena profundizar en ellos para mejor valorar la consistencia de unos nexos que hacen que esta obra entronque sólidamente con las ideas, enfoques y técnicas de algunas de sus novelas anteriores.

Pérez-Reverte pretende dar una imagen del héroe más ajustada a lo que piensa que Rodrigo Díaz pudo ser históricamente y por ello no es casual que se fije en los días iniciales del destierro, cuando, aun habiendo alcanzado cierta notoriedad, todavía no está encumbrado por sus hazañas; contrariamente, nos lo presenta en sus momentos de mayor necesidad, puesto que en medio de las adversidades y en la manera de afrontarlas es donde cada cual demuestra su auténtica talla moral. De hecho, la novela parece pretender responder a una serie de preguntas en torno a cómo una hueste de hombres, más allá de relaciones familiares y los códigos cívicos de época, decide seguir fielmente a un hombre caído en desgracia, y en torno a qué verdaderos requisitos debió poseer éste para que otros lo siguieran con tanta fidelidad. Tanto es así que el protagonista no revela su nombre y procedencia hasta que nos adentramos bastantes páginas en la novela (PérezReverte, 2019: 17). Es como si el autor quisiera minimizar toda la carga legendaria que la tradición ha ido acumulando alrededor de dicho nombre, como si ese peso pudiera haber supuesto un discurso preconstruido o «lejano» que proyectara automáticamente una ideología propia sobre lo que se intenta referir, provocando ocultaciones, tergiversaciones o malas interpretaciones. Frente a esa posibilidad, Pérez-Reverte construye un discurso «de cerca» que intenta, aparenta o pretende dejar hablar, por imposible que esto resulte en última instancia, ya que siempre estamos mediatizados por la voz narrativa; el gesto no es casual ni gratuito, ya que la cuestión de la distancia testimonial, o perspectiva respecto de lo que se quiere dar cuenta, es uno de los centros del discurso revertiano, tal como vienen a ilustrar las palabras de otro personaje del propio autor, Íñigo, en El sol de Breda (1998). Si en ellas intercambiamos «matar» por «narrar», dicho sentido se vuelve evidente:

Quien mata de lejos ninguna lección extrae de la vida ni de la muerte. [...] Quien mata de lejos es peor que los otros hombres, porque ignora la cólera, y el odio, y la venganza, y la pasión terrible de la carne y de la sangre en contacto con el acero; pero también ignora la piedad y el remordimiento. Por eso, quien mata de lejos no sabe lo que pierde. (PérezReverte, 1998: 160-161)

6. Véase, a propósito de la mencionada apropiación de la figura cidiana por parte de los falangistas (aunque antes del final de la Guerra Civil, también por parte del bando republicano), el importante trabajo de Gómez Moreno (2010).

7. Véase con mayor detenimiento, para ese panorama crítico, Hernández (2021). 
Por todo ello, plantear la identidad como una incógnita inicial es situarnos en la casilla de salida en la forja de una personalidad que seguiremos de cerca.

Todo lo anterior, fruto quizá de la experiencia y quehacer de nuestro autor como periodista de guerra durante más de veinte años, y por tanto de su voluntad permanente de comunicar, se articula en la manera de proceder del narrador que conecta con esa labor diaria. El propio autor lo explicó durante una conferencia en 1999:

un periodista va a la guerra a informar, y para informar hay que hacer el trabajo; ahí viene el gran conflicto de todos los corresponsales de guerra: ¿ayudo o trabajo?, ¿filmo o lloro?, pero claro, si lloro no puedo enfocar. Entonces ese conflicto lo solucionábamos haciendo primero el trabajo y, cuando terminábamos, ayudábamos cuando podíamos hacerlo. (Pérez-Reverte, 1999)

En este caso, dicho conflicto tiene que ver con la oscilación, por parte del narrador, entre mostrar (objetivamente) y participar (subjetivamente), intentando generar un discurso cercano y honesto por limitado que éste sea. Esa oscilación podemos apreciarla desde el principio de la novela:

Desde lo alto de la loma, haciendo visera con una mano en el borde del yelmo, el jinete cansado miró a lo lejos. El sol, vertical a esa hora, parecía hacer ondular el aire en la distancia, espesándolo hasta darle una consistencia casi física. La pequeña mancha parda de San Hernán se distinguía en medio de la llanura calcinada y pajiza, y de ella se alzaba al cielo una columna de humo. No procedía ésta de sus muros fortificados, sino de algo situado muy cerca, seguramente el granero o el establo del monasterio.

Quizá los frailes estén luchando todavía, pensó el jinete. (Pérez-Reverte, 2019: 13)

En el primer párrafo encontramos ese mostrar, ese describir objetivamente y de manera escueta por parte del narrador «extradiegético», y justo a continuación, en el principio del segundo párrafo, tenemos el uso del estilo indirecto libre para contarnos lo que piensa el protagonista. De esta manera se establece la «focalización» en ese protagonista de forma predominante a lo largo de toda la novela. Otro ejemplo:

Desde tiempo inmemorial, desde las guerras de los antiguos o desde siempre, la única salvación de los guerreros sin patria era no esperar salvación ninguna.

Pensaba en eso sentado bajo la lona de su tienda, mientras dictaba una carta a fray Millán, el fraile bermejo. Estaba destinada a Jimena, su esposa. Era una misiva fría, casi protocolaria, que daba cuenta de pormenores generales y se interesaba por su estado de salud y por su bienestar y el de sus hijas. (Pérez-Reverte, 2019: 175)

En este caso el orden se da a la inversa: primero el estilo indirecto libre, la participación, y luego la descripción objetiva. El efecto que consigue dicha oscilación es ofrecer la máxima credibilidad: asumimos la descripción de los lugares y las acciones con un alto grado de neutralidad, sin que podamos llegar a sentir la subjetividad del narrador $y$, de forma complementaria, el uso del estilo indirecto libre humaniza al protagonista ante el lector, lo vuelve cercano y por tanto lo aleja del tono legendario o grandilocuente. Así pues, desde la propia configuración de la voz narrativa, esto es, desde el «relato», se instaura, como efecto del narrador, la base de una actitud moral alrededor de la figura del protagonista: el fundamento de la honestidad.

El efecto se amplía con su caracterización, con sus defectos y virtudes y, entre éstas, su liderazgo; de hecho, se ha dicho en diferentes medios que esta obra puede leerse como un manual para ser un auténtico líder. Sin embargo, enfocarlo así, como una guía del tipo El arte de la guerra, de Sun Tzu, deja en claroscuro una parte fundamental de la significación misma de ese «relato», puesto 
que en lo que insiste la narración no es tanto en que Rodrigo Díaz de Vivar devenga un líder por una serie concreta de prácticas, sino en que éstas emanan de un desarrollo previo de su personalidad y de su posición ética (todo ello, sin que la obra caiga en el peligro de la moralización).

Al igual que otros protagonistas revertianos, o más directamente incluso que algunos de ellos (a causa de su destierro), Rodrigo Díaz de Vivar vive una realidad en crisis ante la cual sólo cabe oponer los límites marcados por un espacio moral personal, la fidelidad a una imagen de uno mismo, tal como por ejemplo hacían Astarloa o Alatriste; es decir, los presupuestos de un código de honor propio. Es cierto que los códigos éticos públicos de la época exigían de un vasallo fidelidad absoluta hacia su señor, salvo en determinadas circunstancias, como bien se explica en la conversación que mantienen Berenguer Remont II y Rodrigo Díaz, cuando éste va a ofrecerle sus servicios:

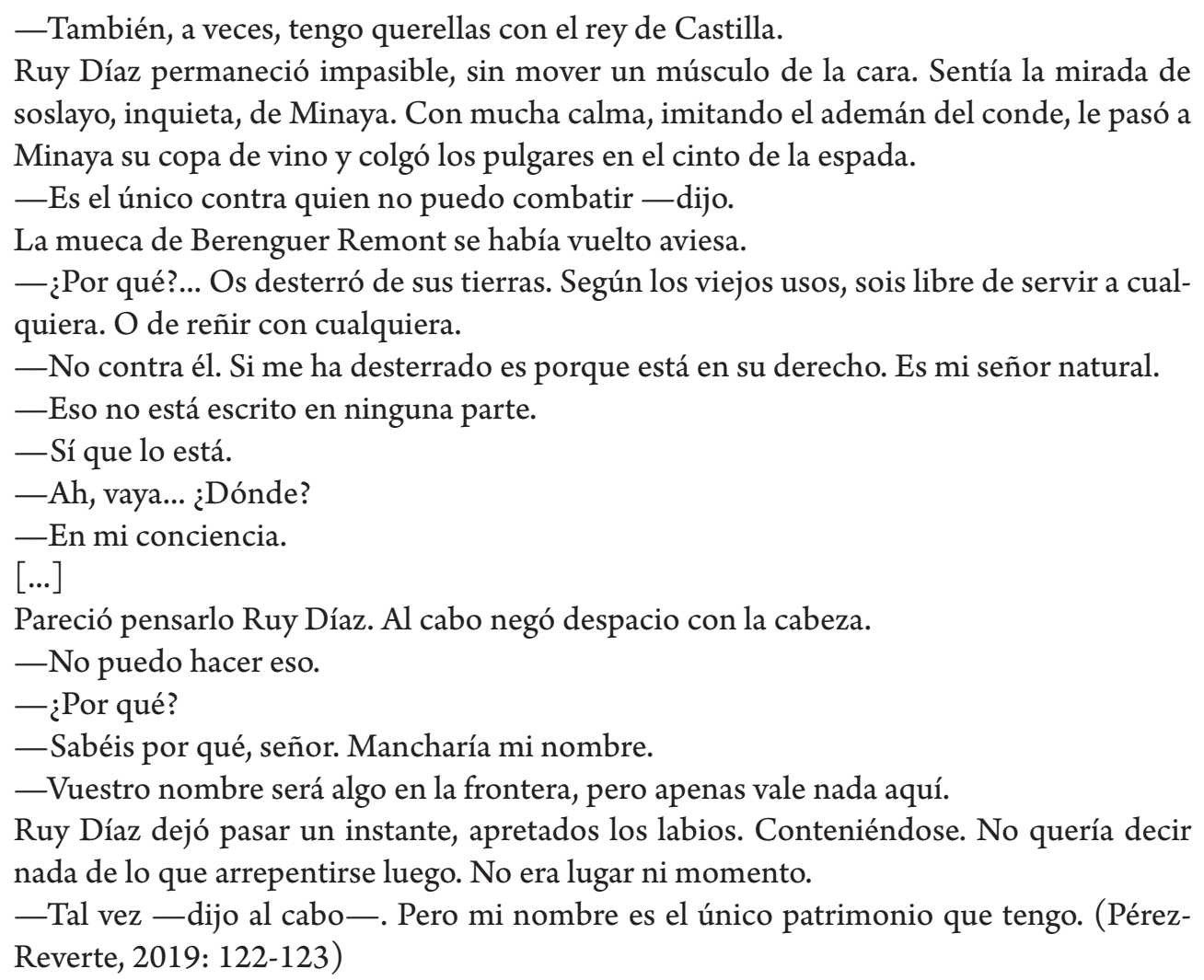

Lo que ilustra Díaz de Vivar en este diálogo es aquella máxima de Nietzsche, en Así habló Zaratustra: «Supérate a ti mismo incluso en tu prójimo: iy un derecho que puedas robar no debes permitir que te lo den!» (2021: 327). El filósofo alemán defiende que el ser humano debe crear sus propios valores; su «súper-hombre» $\mathrm{u}$ «hombre noble» (siempre en sentido moral) es creador de ellos. Sin embargo, todo está inventado y de ahí la máxima citada: a lo que se refiere es a la tradición, a una tradición (o herencia de valores; pasividad) como algo no-pensado y directamente asumido sin ningún tipo de revisión crítica; «robar un derecho» quiere decir hacer una revisión crítica (activa) de ese derecho o principio moral y la consecuente decisión de asumirlo o no. En el caso de asumirlo, lo hemos hecho nuestro o, mejor dicho, deja de ser algo exterior a uno mismo y forma parte ya del propio ser con todas las consecuencias que ello conlleva.

Eso es lo que ha hecho Rodrigo Díaz. La fidelidad al señor ha dejado de ser para él un código preestablecido de conducta y pasa a ser un valor moral propio, de manera que se erige en sí mismo 
como una conciencia libre, algo que queda refrendado en palabras del propio Díaz de Vivar, cuando dice que está escrito en su conciencia. Las palabras de Mutamán durante una conversación posterior con Díaz de Vivar confirman este sentido:

- Por supuesto... Me estás diciendo que, en realidad, tu rey es lo de menos. Me refiero a la persona. Es la idea, ¿no?... Eres uno de esos raros hombres fieles, no a una persona sino a una idea. En tu caso, una idea egoísta: la que tienes de ti mismo.

Ruy Díaz reflexionó otra vez. Lo cierto era que nunca se había planteado eso. O no de tal modo. Su oficio no era rumiar esa clase de cosas.

-Es posible —admitió.

- Claro que lo es. Por eso hay quienes no se traicionan nunca, aunque en torno se les hunda el mundo. Incluso en la negrura de la noche, cuando nadie los ve... No hay lealtad tan sólida como ésa.

Seguía sonando la voz del almuédano, doblada en los cerros cercanos como un eco distante. Ruy Díaz hizo un ademán de indiferencia.

- Sólo es importante el final de las cosas.

Lo miró el rey casi con sorpresa. Cual si algo notable se acabara de desvelar ante sus ojos. -Es lo que desearías cuando llegue, ¿verdad?... Un final que lo confirme todo.

Seguía mirando Ruy Díaz por la ventana, sin responder. La oración pregonada desde el minarete parecía atraer su atención. (Pérez-Reverte, 2019: 263)

«Un final que lo confirme todo»: a eso exactamente se refiere la expresión «muerte honorable». Es decir, a una muerte acorde a los principios morales que han regido la propia existencia (sea cual sea el oficio o condición). La coherencia con esos principios es lo que llamamos (o deberíamos llamar) honor. Ese mismo deseo que detecta Mutamán lo reconocerá también, en cierta forma, el personaje de Olvido en Faulques, protagonista revertiano de El pintor de batallas (2006). La variación en el grado de posesión de dicha concepción moral del honor es lo que caracteriza a estos distintos protagonistas revertianos.

El héroe, en Pérez-Reverte, no lo es por acciones casi sobrehumanas, sino todo lo contrario: su acción se fundamenta en resortes morales personales sin llegar — tal como comentábamos anteriormente - al moralismo. El grado de posesión se identifica mediante la aproximación a una de las cuatro figuras revertianas, presentadas en dos pares, que sirven para la caracterización del personaje estableciendo una gradación de menor a mayor ${ }^{8}$. Siguiendo ese orden, la primera sería la figura del depredador, aquél entregado a su ansia de destrucción y violencia sin importar lo que ello conlleve, tan sólo por sentir el efecto energizante de la adrenalina en la lucha por poseer y destruir, o destruir poseyendo; sin prácticamente más principio que ese instinto. En el caso de Sidi, el personaje de Diego Ordóñez ocuparía ese lugar por el comentado efecto revitalizador o de plena conciencia de uno mismo ante la proximidad de la vorágine. Lo podemos apreciar en dos hechos concretos. El primero, su reacción al presentarse el duelo de campeones previo a la batalla final:

Estaban detenidos cerca de los otros. Sonó entonces la risa feroz de Diego Ordóñez, y cuando Ruy Díaz miró en su dirección vio que aquél le había pasado la enseña a Félez Gormaz.

—A mis hijos podrán llamarlos hijos de puta —masculló el burgalés—, pero no hijos de cobarde.

Y acto seguido, tras embrazar el escudo y sacar la espada, clavó con violencia las espuelas en los ijares de su caballo, alzándolo de manos antes de lanzarse adelante.

8. Tal como desarrolé en Hernández (2021). 
Qué animal, pensó Ruy Díaz. Qué brutísimo animal.

Pasó Ordóñez cabalgando pendiente abajo junto al jefe de la hueste y el capitán moro, en dirección al vado; y se oían carcajadas de gozo tras la malla de acero que le tapaba la barba y la boca.

Era cuanto Diego Ordóñez necesitaba para ser feliz, asumió resignado Ruy Díaz. Un día con bonita luz, un caballo, un enemigo y una espada. (Pérez-Reverte, 2019: 282)

El segundo, después de la batalla, cuando aparece luciendo un cinturón con las orejas hilvanadas de los rivales que ha matado:

Diego Ordóñez se unió a ellos. El burgalés había trocado su habitual aire de ceñuda ferocidad por una sonrisa satisfecha aunque no menos feroz. Aún imponía más su aspecto, con la cota de malla manchada de polvo y sangre seca, el vendaje rojizo que le cubría del cuello a la sien y el rosario de orejas enemigas cortadas: una veintena ensartadas en un cordel que pendía de su cinto junto a la daga y la espada. Había vengado de sobra la suya, perdida en el campo de batalla. (Pérez-Reverte, 2019: 341)

La siguiente figura es la del cazador; símbolo de la anulación de los términos opuestos de civilización/barbarie. El propio cuerpo del cazador, expuesto a los efectos de lo siniestro, sirve de campo de contienda para la develación de lo que siempre ha estado en la naturaleza humana: la crueldad. En cuanto que elimina la dualidad de aquellos antónimos, también participa de ellos simultáneamente, y eso es lo que evita que se convierta completamente en un depredador. Ése es su reverso: en la obtención de sus objetivos puede moverse guiado por una moralidad menos (auto) exigente. El narrador de Territorio comanche decía precisamente de Márquez que «le daba igual que la imagen se emitiera o no, porque el suyo era simple impulso de cazador: lo que necesitaba era tenerlo» (Pérez-Reverte, 1994: 38). En otro momento:

Sí. Kukunjevac fue la guerra de verdad, y no existía Hollywood capaz de reconstruir aquello: el cielo gris, los soldados moviéndose por la carretera, las casas ardiendo. Y la sensación de peligro, tristeza inmensa, soledad, que transmitía la imagen ligeramente torcida de la cámara de Márquez. Barlés lo recordaba caminando entre los soldados con la Betacam en la cadera, inexpresivo, las aletas de la nariz dilatadas y los ojos entornados, saboreando la guerra. Y tenía la certeza absoluta de que ese día, en Kukunjevac, Márquez había sido feliz. (Pérez-Reverte, 1994: 71, 72)

En el otro par de figuras, la del mercenario es la que ocupa la posición de menor nivel, aunque en sí misma posee matices. Muchas veces nuestro autor, para referirse a su propia actividad como reportero de guerra, decía que era un mercenario honrado, dependiente de una discursividad oficial para la realización de su trabajo. No obstante, menosprecia esa oficialidad por no ser capaz de ahondar de verdad en los conflictos y barbaridades que él testimonia, llegando a penas a tocar la superficie. Dicha condición es aplicable a nuestra relación personal con el sistema social: las personas que no son capaces de establecer límites, vendiéndose completamente a los intereses del sistema en el desarrollo de su labor, serían los mercenarios deshonestos: «hay mil formas, según la conciencia de cada cual, de pelear, pero hay que pelear, porque, si no, somos mercenarios deshonestos, somos basura a merced del primero que llega» (Pérez-Reverte, 1999). Alatriste y Malatesta, en su primera misión juntos (El capitán Alatriste [1996]), representarían ambas condiciones respectivamente.

El otro miembro del par también es ocupado simultáneamente por Alatriste en su labor de soldado y es la figura que se puede aplicar a Rodrigo Díaz de Vivar. Se trata de la figura tipificada 
del guerrero samurái y su código de honor, el bushidō. Figura indispensable para entender otras obras del propio Pérez-Reverte, como la mencionada El pintor de batallas, el samurái representa al guerrero que es capaz de mantener su humanidad y ética pese a estar inmerso en la vorágine de la batalla, tal como podemos apreciar en los sietes principios en los que el orientalista Norberto Tucci sintetiza el código bushidō $\bar{o}^{9}$. Resulta evidente la coincidencia de estos principios, en términos generales, con la actitud de Rodrigo Díaz a lo largo de toda la novela, a tenor de lo comentado previamente; de hecho, en la pugna final de la obra que nos ocupa, se nos dice que «Ruy Díaz había matado al último, un caballero franco de buen aspecto al que ofreció cuartel y no lo quiso» (Pérez-Reverte, 2019: 331). Por tanto, le ofreció perdonarle la vida. Siguiendo el paralelismo sugerido, se podría decir que la imagen proporcionada de Díaz de Vivar resulta próxima, salvando las distancias, a la del ronin, un samurái sin señor que vaga de un lado a otro y, pese a ello, logra mantener su fidelidad intacta. Ya que es una decisión que adopta por sí mismo, a quien está siendo verdaderamente fiel es a él mismo, a su concepción de sí y del mundo.

Existe otro engarce para captar mejor dicha comparación. En una entrevista concedida por el autor, a propósito de la obra que nos ocupa, apunta que «en la novela se remarca algo que quizá choque para el lector de hoy: morir con naturalidad. En Occidente rechazamos que la muerte forma parte de las reglas del juego»; y, a continuación, señala: «el orgullo tiene mala prensa, se confunde con la soberbia. El orgullo, cuando vienen momentos de crisis, de caos, es útil porque te mantiene erguido. Es primo hermano de la dignidad. La soberbia no, la soberbia te ciega. El Cid es orgulloso» (Llorente, 2019).

Si existe una cultura que naturaliza la muerte es precisamente la relacionada con el código del bushidō, el camino del guerrero samurái: «se vive plenamente o se muere». Orgullo y muerte quedan entrelazados de manera que un samurái siempre buscará una muerte digna o entenderá que la única vía decorosa tras el fracaso ante ese caos - al que se refería Pérez-Reverte en la cita anterior- es el suicidio. De manera que no es un agente externo quien vence al guerrero, sino éste a sí mismo: un guerrero quita la vida a un guerrero. Esa incomprensión occidental la encontramos ya precisamente en los personajes de una novela que ha intentado reflejar esa imagen del guerrero oriental: Shogun (1975), de James Clavell. Se trata de una novela que nuestro autor ha llegado a calificar como obra extraordinaria y a afirmar que es por la que empezó a comprender mejor la cultura japonesa (Pérez-Reverte, 2020). El orgullo u honor es el límite que decidimos establecer para no dejar de ser nosotros mismos pese a las influencias externas. Y ese límite o margen lo comparten Rodrigo Díaz de Vivar y el guerrero oriental, y lo mantendrán hasta el último extremo, aunque ello implique la muerte. Decía Nietzsche que libre es quien puede prescribirse a sí mismo su bien y su mal, y suspender su voluntad por encima de sí mismo, como un legislador, pudiendo ser juez para sí mismo y vengador de la propia ley (Nietzsche, 1883: 123). Pérez-Reverte, en ese

9. Se consignan en su edición de Hagakure, obra del antiguo samurái Yosho Yamamoto (2004): [1] Gi. Honradezy justicia en la acción. La decisión debe ser justa y ecuánime, la justicia auténtica emana de tu interior. No hay término medio en este campo, ni medias tintas, o es justo o injusto, se vive plenamente o se muere. [2] Yu. Valor heroico y bravura en la acción. No hay que temer la acción, ni ocultarse del exterior. Hay que ser arriesgado. Hay que vivir plenamente, ésta es la verdadera inteligencia. Miedo no, preocupación y respeto sí. [3] Jin. La compasión o el amor universal. El samurái es fuerte y por ello ha de estar al servicio de los demás que no lo son. Su poder debe ser usado en bien de todos, ayuda a sus compañeros y al prójimo. [4] Rei. Cortesía. No hay motivo para ser crueles, no hay que demostrar la fuerza. Cortesía y respeto hacia a todos, incluso hacia los enemigos. En los peores momentos es cuando se demuestra la fuerza interior. [5] Melyo. Honor. El honor es el valor principal a defender, por él se obtiene la gloria. Los actos denotan la personalidad y el carácter. Nadie se puede ocultar de ellos. [6] Makoto. Sinceridad absoluta. Lo que dice, así hace. No tiene que «prometer» nada. Todo lo cumple. Hablar y Hacer son la misma acción. [7] Chugi. Deber y lealtad. Cumplir con las obligaciones de su puesto frente a sus superiores de rango y ser leal a los que están bajo su responsabilidad. 
sentido, viene a «transculturizar» en cierta forma la figura del guerrero oriental en la del guerrero castellano.

Con esas dos figuras (cazador y samurái) y con sus respectivos reversos (depredador y mercenario) - cuatro, por tanto, si se quiere-, nuestro autor dibuja un posicionamiento antropológico, moral y estético, en una gradación de las dos opciones contrapuestas, que evita el maniqueísmo y evidencia las marcas o cicatrices de quien ha pretendido captar lo siniestro allí donde el barniz civilizado falla. De manera que frente a la habitual concepción de la bondad natural o frente a la común alusión a la influencia de las circunstancias como explicación del ser humano, nuestro autor, desde su punto de vista, hace emerger en su novelística la crueldad u oscuridad propias de todo individuo. La actitud que mantengamos frente a esa crueldad, ya sea de entrega o de resistencia, determinará nuestra ética personal y quiénes seamos, tal como les sucede a buena parte de sus protagonistas. Y es así como, a lo largo de las páginas de Sidi, Rodrigo Díaz va construyendo esa identidad aplazada inicialmente y lo va haciendo más por su esencia moral que por su esencia de guerrero. Pérez-Reverte nos ofrece un héroe moral antes que militar. Una vez constituido el héroe moral, sus prácticas pueden ser leídas como un manual de liderazgo, pero no al revés. El orden de los factores sí que altera el producto.

Se podría decir, finalmente, que existe otro paralelismo heroico y literario que pudo inspirar a nuestro autor: la figura de Ulises. El héroe griego no podía regresar a casa, dadas las trabas impuestas por el dios Poseidón, airado porque había dejado ciego a su hijo Polifemo. El castellano es desterrado por un rey, representante de dios en la tierra. En ambos, por similar causa, destaca un exceso de audacia. Rodrigo Díaz de Vivar ansía volver a ver a una Jimena que le espera paciente, cual Penélope. De hecho, el escarceo amoroso que el Cid, Sidi, vivirá con Raxida, hermana del rey moro de Zaragoza, bien podría considerarse un trasunto condensado de los años que el griego pasa con Calipso antes de volver a Ítaca.

La oscilación entre mostrar y participar apunta, en fin, a un límite discursivo; en este caso, ese límite tiene que ver con una doble ceguera (entendiendo por ésta aquello que escapa a la representación discursiva): una, la histórica (en cuanto que poco testimonio fehaciente queda de la vida del Campeador) y otra, el horror bélico. La primera ceguera se refiere a la interrelación entre historia y literatura: allí donde el discurso histórico encuentra espacios en blanco, la literatura puede trabajar, desde los márgenes, rellenando vacíos con mayor o menor coherencia con el objetivo de facilitar una comprensión de lo que pudo haber sido. Ya decía Aristóteles en su Poética que la literatura (o poesía, como término equivalente) le parecía, en ese sentido, más filosófica y elevada que la historia.

La segunda ceguera se refiere a la interrelación entre literatura y horror bélico; la violencia como exceso que no puede ser atrapado totalmente en un discurso, pero que sí puede ser delineado por éste mediante lo metafórico, lo metonímico, lo siniestro y demás recursos expresivos o figuras retóricas, de manera que su representación - la de esa violencia- quede como un espacio sintomático y limítrofe (Trías, 2006). Dos cadáveres (o uno, en otras obras del autor) junto a un sendero son, junto con las columnas de humo - aunque no en este caso- los primeros síntomas revertianos de la violencia: «Había dos cadáveres junto al sendero, entre los pinos y enebros que crecían al pie de la muralla. Llevaban allí dos días y empezaban a oler fuerte. Se los adivinaba por eso y por el zumbido de las moscas» (Pérez-Reverte, 2019: 217). Finalmente, una vez comenzada la batalla, todo queda enmarcado en ese espacio de no-visión, donde se desenvuelve el horror, aquí causado representativamente por la polvareda de las diferentes cargas: 
Y cuando cerca del enemigo la señal de Diego Ordóñez ondeó a un lado y a otro, los suyos espolearon para ponerse al galope, la polvareda creció hasta ocultarlo todo y a través de ella se oyó el griterío de los hombres que mataban y morían. (Pérez-Reverte, 2019: 312)

Dicho espacio es lo que en Territorio comanche (1994) se denomina de manera homónima (es decir, «territorio comanche $»)$ :

Era lo que ellos llamaban territorio comanche en jerga del oficio. Para un reportero en una guerra, ése es el lugar donde el instinto te dice que pares el coche y des media vuelta. El lugar donde los caminos están desiertos y las casas son ruinas chamuscadas; donde siempre parece a punto de anochecer y caminas pegado a las paredes, hacia los tiros que suenan lejos, mientras escuchas el ruido de tus pasos sobre los cristales rotos. El suelo de las guerras está siempre cubierto de cristales rotos. Territorio comanche es allí donde oyes crujir bajo tus botas, y aunque no ves a nadie sabes que te están mirando. Donde no ves fusiles, pero los fusiles sí te ven a ti. (Pérez-Reverte, 1994: 16-17)

Bajo la metáfora del «territorio comanche» se designa un exceso ciego de lo siniestro que emerge, un espacio sintomático que establece una relación metonímica de contigüidad, que cuestiona cualquier discurso que pretenda atraparlo, siendo límite del mismo y condición de ser; por lo que se puede decir que esa batalla final, como cualquier escenario de violencia, es «territorio comanche» para un discurso que intente testimoniar, y más allá del cual sólo existen imágenes aberrantes de crimen que nos impactan y sobrecogen anulando toda posibilidad de expresión (Trías, 2006).

Se puede decir, en conclusión y atendiendo a todo lo expuesto, que el subtítulo de la obra que nos ocupa - Un relato de frontera - cobra, por diferentes correspondencias, más sentido que nunca.

Podría leerse una primera correspondencia (metafórica) entre el espacio fronterizo donde se desarrolla la acción y la frontera discursiva respecto al horror bélico. Éste en esencia queda más allá de la narración, aunque sea delineado por ella.

Una segunda correspondencia sería respecto a la frontera moral entre la ética propia del protagonista y el mundo caótico, en crisis, en el que se ve envuelto y que intenta arrastrarlo a la pérdida de su integridad.

La tercera tendría que ver con el límite o posición otra de la propia interpretación revertiana sobre el Cid, frente a las versiones dominantes fuertemente ideologizadas (tal como denunciara el propio autor).

Y, por último, el subtítulo - y el contenido del propio título: el personaje- se correspondería también con la frontera entre historia y literatura, con ese margen en el que ambas confluyen desde sus divergentes cauces en la propia novela.

Mediante la superposición (metafórica) de todas estas fronteras, moral, teoría literaria y escritura quedan imbricadas indisolublemente.

\section{Bibliografía}

Alvar, Carlos y Manuel Alvar (eds.) (1997), Épica Medieval Española, Madrid, Cátedra. Borx Jovaní, Alfonso (2021), «De Per Abbat a Pérez-Reverte: el Cid, entre la tradición y el superventas en Sidi», Monografías Storyca [en línea]. http://parnaseo.uv.es/AulaMedieval/ aM_es/StorycaWeb/de-per-abbat-a-perez-reverte-el-cid-entre-la-tradicion-y-el-superventasen-sidi/ 
Clavell, James (1975), Shogun, Barcelona, Círculo de Lectores.

FletCher, Richard $\left(2001^{3}\right)$, El Cid, Hondarribia, Nerea.

Fuentes, Antonio (2020), El Cantar de Mío Cid en Sidi de Arturo Pérez-Reverte. Girona, Universitat de Girona.

GenetTe, Gérard (1989), Figuras III. Barcelona: Lumen. [ed. original: Figures III, París, Editions du Seuil. 1972]

Gómez Moreno, Ángel (2010), «El Cid y los héroes de antaño en la Guerra Civil de España», eHumanista, 14, pp. 210-238.

HERNÁNDEZ RUIZ, Francisco Javier (2021), Imagen y narración: el discurso sobre la guerra en Territorio comanche, El pintor de batallas y El francotirador paciente de Arturo Pérez-Reverte, Tesis doctoral, Valencia, Universitat de València. https://roderic.uv.es/handle/10550/78093

Llorente, Manuel (2019), «Arturo Pérez-Reverte: "El orgullo es útil en momentos de crisis porque te mantiene erguido" $\gg$, El Mundo [Suplemento de Cultura, 8 septiembre --] https:// www.elmundo.es/cultura/literatura/2019/09/18/5d8267f821efa006688b45a3.html

Montaner Frutos, Alberto (ed.) (2011), Cantar de Mio Cid, Madrid, Real Academia Española-Barcelona, Galaxia Gutenberg-Círculo de Lectores.

Muñoz OgáYar, Jorge (2009), Y al séptimo día descansó. Arturo Pérez-Reverte, creador de universos postmodernos, [s. 1.], Nausícaä.

Nietzsche, Friedrich (2021), Así habló Zaratustra, Madrid, Alianza.

Pérez-Reverte, Arturo (1994), Territorio comanche, Madrid, Ollero \& Ramos.

y Carlota Pérez-Reverte (1996), El capitán Alatriste, Madrid, Alfaguara.

(2000), El sol de Breda edición empleada (2000), Madrid, Alfaguara [ed. orig. 1998].

(2006), El pintor de batallas, Madrid, Alfaguara.

(2019), Una historia de España, Madrid, Alfaguara.

(2019), Sidi. Un relato de frontera, Madrid, Alfaguara.

(2020), La cueva del cíclope. Tuiteos sobre literatura en el bar de Lola (2010-2020), Madrid, Alfaguara [edición digital].

[Conferencia] Pérez-Reverte, Arturo (2014 [1999]) «La cobertura periodística del siglo $\mathrm{XX} \gg$, conferencia impartida ante estudiantes de Periodismo y Medios de información en el Instituto Tecnológico y de Estudios Superiores de Monterrey. 18 de marzo de 1999, Monterrey (México), Cátedra Alfonso Reyes. https://www.youtube.com/watch?v=sN6bl7BecfM TríAs, Eugenio (2006), Lo bello y lo siniestro, Barcelona, Ariel.

Yамамото, Yosho (2004), Hagakure. El código secreto del Samurái, Madrid, Librería Argentina. 